Association for Information Systems AIS Electronic Library (AISeL)

Wirtschaftsinformatik Proceedings 2003

Wirtschaftsinformatik

September 2003

\title{
Inter-Organizational Disruption Management Based on Flexible Integration with Web Services
}

Jochen Klaus Speyerer

FORWIN - Bavarian Research Networkfor Information System, speyerer@forwin.de

Andrew John Zeller

FORWIN - Bavarian Research Network for Information System

Follow this and additional works at: http://aisel.aisnet.org/wi2003

\section{Recommended Citation}

Speyerer, Jochen Klaus and Zeller, Andrew John, "Inter-Organizational Disruption Management Based on Flexible Integration with Web Services" (2003). Wirtschaftsinformatik Proceedings 2003. 94.

http://aisel.aisnet.org/wi2003/94

This material is brought to you by the Wirtschaftsinformatik at AIS Electronic Library (AISeL). It has been accepted for inclusion in Wirtschaftsinformatik Proceedings 2003 by an authorized administrator of AIS Electronic Library (AISeL). For more information, please contact elibrary@aisnet.org. 
In: Uhr, Wolfgang, Esswein, Werner \& Schoop, Eric (Hg.) 2003. Wirtschaftsinformatik 2003: Medien - Märkte - Mobilität, 2 Bde. Heidelberg: Physica-Verlag

ISBN: 3-7908-0111-9 (Band 1)

ISBN: 3-7908-0116-X (Band 2)

(C) Physica-Verlag Heidelberg 2003 


\title{
Inter-Organizational Disruption Management Based on Flexible Integration with Web Services
}

\author{
Jochen Klaus Speyerer, Andrew John Zeller \\ FORWIN - Bavarian Research Network for Information Systems
}

\begin{abstract}
The current political and economical instabilities once again emphasize the need for companies to swiftly react to disruptions within their supply network and flexibly integrate with multiple partners. However, there has only been limited research into this area in the context of networked organizations. This paper introduces an inter-organizational approach for gauging the impact of exceptions once they occur, identifying their root causes and eventually taking action to remedy them. Depending on the seriousness of each disruption information will be intelligently disseminated only to those stakeholders requiring to get notified. We close with presenting a web services-based prototype that has been built at the Bavarian Research Network for Information Systems (FORWIN) describing the alerting component in more detail.
\end{abstract}

Keywords: Supply Chain Management, Disruption Management and Controlling, Flexible Integration, Web Services, Networked Organizations

\section{Disruptions in supply networks}

\subsection{The need for flexible disruption handling}

Although most supply chain planning and controlling models imply relatively stable settings, reality proves them wrong. Not only the recent terrorist attacks and natural disasters have wreaked havoc upon the coordination of supply and distribution structures but also everyday-exceptions like the breakdown of a production line or late deliveries show the need for a comprehensive disruption management. To date, supply managers spend up to $60 \%$ of their daily working time coping with exceptions, identifying alternatives and notifying stakeholders as well as expediting actions [MuLe02]. Bretzke goes even further and lifts up this figure to $80 \%$ [Bret02].

Apparently, the ability to efficiently react to disruptions has become a key success factor for companies to gain or sustain market share and deliver exceptional customer service. In their "logistical footprint", a study on how to achieve logistical 
excellence, well-known consulting firm Accenture even proclaims this skill to be a core capability [Hebe02].

Nevertheless, each supply chain-oriented approach has to cope with networkspecific problems:

1. Supply networks are not stable and subject to reconfiguration.

2. Corporations do not participate in only one net at a time but in several.

3. The interrelationship between enterprise and supply chain performance must be taken into account [LaPo01].

4. Networks do not merely consist of a few big players but also of small and medium sized enterprises (SME). Due to an usually restricted budget and limited know-how these companies cannot afford the well-known full-scale software solutions [Spey00].

5. Although companies cooperate in networks, their mutual dependency can still be characterized as partly competitive (Co-opetition [BuKo00, p.52]).

But also technological advances underscore the possibilities for further research. The application of web services to typical business processes call for new architectures and methods of transcorporate integration [FrSp03] and the ability of database technology to handle terabytes of data fosters new decision-support approaches. As Friedrich [Frie02] showed, the application of distributed components based on ubiquitous Microsoft Office elements lets also SME harvest some of the benefits of supply chain integration without having to invest enormously beforehand. All these developments prove the technological foundation for interorganizational disruption management exists but needs further improvement.

Thus, no monolithic framework will satisfactorily fulfill these specific requirements. Instead, the approach will have to allow for companies to flexibly integrate into multiple networks and, if necessary, into various electronic marketplaces. To fill this need, the Bavarian Research Network for Information Systems (FORWIN) is developing a web services-based decentralized system that identifies disruptions, evaluates their impact on the supply chain and disseminates information only to those stakeholders who need to be informed.

\subsection{Internal vs. external disruptions}

Before getting into details, it is necessary to clarify the terminology used throughout this paper. Unfortunately, the application of the term disruption does not seem to be clear-cut. It can correspond to either the deviation of a value from its target or whatever causes this deviation. Therefore, we will use symptom for any measured deviation and root cause to refer to the source of the symptom whereas the term disruption encompasses both. If supply chains encounter disruptions they 
usually do not know whether they are facing a symptom or a root cause before conducting a thorough analysis.

\begin{tabular}{|c|l|l|l|}
\hline Date & \multicolumn{1}{|c|}{ Crisis } & \multicolumn{1}{|c|}{ Disruption } & Example for impact \\
\hline $\begin{array}{c}\text { October } \\
1998\end{array}$ & $\begin{array}{l}\text { Hurricane Mitch in } \\
\text { Honduras, Guatemala }\end{array}$ & $\begin{array}{l}\text { Destruction of banana } \\
\text { plantations, damaging } \\
10 \% \text { of worldwide } \\
\text { crops }\end{array}$ & $\begin{array}{l}\text { Dole Food Company, Inc. } \\
\text { unable to deliver, struggled } \\
\text { hard to find alternative sup- } \\
\text { pliers. Stock-outs at retail } \\
\text { sites }\end{array}$ \\
\hline $\begin{array}{c}\text { September } \\
1999\end{array}$ & $\begin{array}{l}\text { Earthquake in Tai- } \\
\text { wan }\end{array}$ & $\begin{array}{l}\text { Power outages and } \\
\text { destruction of produc- } \\
\text { tion sites and equip- } \\
\text { ment interrupted sup- } \\
\text { plies to PC component } \\
\text { manufacturers }\end{array}$ & $\begin{array}{l}\text { Inflexible product configura- } \\
\text { tions and little inventories } \\
\text { stifled Apple's assembly } \\
\text { lines }\end{array}$ \\
\hline $\begin{array}{c}\text { September } \\
2001\end{array}$ & $\begin{array}{l}\text { Terrorist attacks on } \\
\text { World Trade Center } \\
\text { and the Pentagon }\end{array}$ & $\begin{array}{l}\text { Increased internal se- } \\
\text { curity measures, } \\
\text { tighter controls at bor- } \\
\text { ders. International } \\
\text { shipments extremely } \\
\text { delayed }\end{array}$ & $\begin{array}{l}\text { Ford had to close down 5 } \\
\text { plants for a number of days } \\
\text { due to lack of production } \\
\text { materials }\end{array}$ \\
\hline $\begin{array}{l}\text { Fooding in Eastern } \\
\text { Germany }\end{array}$ & $\begin{array}{l}\text { Damaged equipment } \\
\text { and infrastructure, } \\
\text { destruction of produc- } \\
\text { tion facilities }\end{array}$ & $\begin{array}{l}\text { Train service to major cities } \\
\text { interrupted for a number of } \\
\text { weeks due to destruction of } \\
\text { tracks and feeder wires. } \\
\text { Meissen, manufacturer of } \\
\text { fine china, closed down pro- } \\
\text { duction. Volkswagen was cut } \\
\text { off from supplies and had to } \\
\text { run Dresden plant under ca- } \\
\text { pacity }\end{array}$ \\
\hline
\end{tabular}

Table 1: Overview of recent crises

On a high abstraction level we can distinguish between disruptions due to network-internal problems and those caused externally. The latter ones include labor strikes, natural disasters and political upheavals. Unfortunately, the past few years have witnessed a multiplication of these. Apart from the devastating legacy these incidents left on most countries involved, economies will have to shape up again 
and acknowledge the fact that dealing with disruptions and instabilities seems to have become a part of business life. Table 1 gives a brief overview of recent crises and some of their effects [MaSu02].

Other disruptions external to the network can be found on the demand side. If, e. g. the customer all of a sudden decides not to buy the ordered product after all or, more general, patterns of consumption change, the supply chain partners will have to adapt but probably will not be able to apply therapeutic measures to fight the root cause.

Network-internal exceptions occur in direct functions, e. g. production, transportation, shipping, or indirect functions like planning and information management. In a manufacturing environment it is also necessary to check whether or not the critical path is affected. A typical example for disruptions in this category is a retailer experiencing stock-outs because of a specialty machine at the manufacturer's being out of order.

Here we also have to distinguish between exceptions occurring executing a process or planning it. If for any reason target values and schedules have been erroneously computed the execution process will make the impression of being disrupted, although the root cause is to be found in planning.

\section{Disruption management}

\subsection{Previous work on disruption management}

Previous research on disruption handling and supply chain coordination has mainly adopted three distinct approaches:

- intra-company handling of disruptions

- decentralized management of supply nets and transports

- Supply Chain Event Management

Readily available literature on disruptions focuses on rescheduling job-shops and optimizing production activities within a single company [BeMe96; Pati02; Wild95]. Although detailed analysis and useful insight is provided, these approaches do not and, due to their very nature, cannot in-corporate supply netspecific problems.

New concepts for decentralized management of networks usually employ agent technology to represent independent decisions of co-operating enterprises [GaWa02; Kreb02]. Although publications in this area reach from more generic methodologies [WoCi99] to concrete applications of agents in marketplaces con- 
testing in optimization tournaments [DoK+02], the major shortcoming is either the lack of exception handling capabilities or the missing of an overall framework for disruption management.

Only recently have commercial software vendors like $\mathrm{SAP} \circledast$, Vigilance $\AA$, Inc. and SeeCommerce ${ }^{\circledR}$ begun to conquer the market potential by offering so-called Supply Chain Event Management Systems [Knic01]. The revolutionary idea of these systems is to support the required transcorporate decision-making process in case of disruptions all the way from diagnostics to rigorous deployment of long-term therapeutic measures [LeAm02; Mert02]. However, most available systems so far merely transfer the idea of workflow management to a network of companies. Each activity gets a status assigned that a central SCEM system monitors by comparing it against a network schedule. In case of any deviations an alert is issued [Niss02; WiLa01]. Unfortunately, diagnostic and therapeutic modules still seem to be underdeveloped.

\subsection{Symptom-to-therapy cycle}

Reactions to problems in supply networks can be grouped according to two factors: their solution orientation and their ability of support identification of the root cause. This classification leads to the 4-quadrant portfolio presented in Figure 1. Starting in cell I it is possible to move to either quadrant II or III. Having conducted all analyses necessary, the motion ends in cell IV, a full-scale therapy of the problem.

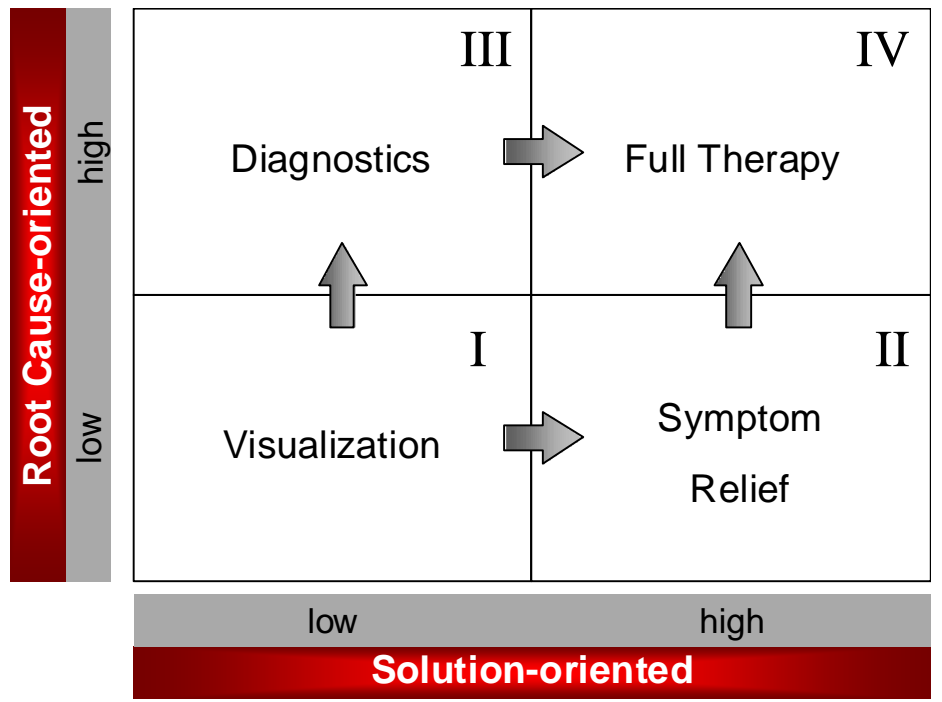

Figure 1: Disruption management portfolio 
Visualizing processes within the entire supply chain builds the foundation for all subsequent activities from diagnosis to full-scale therapy. In our case, visualization consists of:

- Alerting

- Performance measurement

- Information screening

While alerts take care of acute, unexpected occurrences within the supply chain, performance measurement focuses on long-term evaluation of network functions. So far, commercially available SCEM products solely stick to alerting. For an indepth problem analysis, however, this seems to be too narrow. Whereas the first two points focus on reacting to what is already about to happen, information scanning retrieves information from external sources (e. g. current weather condition at destination, actual waiting times at cross-border checkpoints) and is supposed to detect problems ahead of time to give networks a head start in proactively steering clear.

A viable disruption management system must measure long and short-term performance using a defined set of metrics and be able to identify possible exceptions. A fictitious example could be a soaring breakdown rate of trucks. In addition to collected (historical) disruption data, the system would have to analyze past performance and other metrics like maintenance and repair costs, frequency of shipments, distance between locations etc. Based on this large data pool similar patterns can be discovered and assessed.

Moving to quadrant II, the focus shifts to taking actions. Having identified disruptions, measures need to be taken to steer clear of these problems. However, to alleviate any problems caused by disruptions companies have to deploy emergency actions as soon as possible and thus do not have the time to consult with the majority of partners, provided the node experiencing the exceptions is not the focal orchestrator.

Despite this possibility for a quick remedy, this quadrant does not include a thorough analysis of the root cause. Sticking to the above introduced transportation example, actions taken would include finding a new logistics provider to fill in for the lost shipment.

To find out more about the underlying causes of the disruption, the system needs to conduct a diagnostic study. Employing both long-term performance measurement data and alerts concerning current disruptions, possible root causes are retrieved from an expert system and matched against the symptoms presently experienced to come up with a likely source of the problem (Figure 2). 

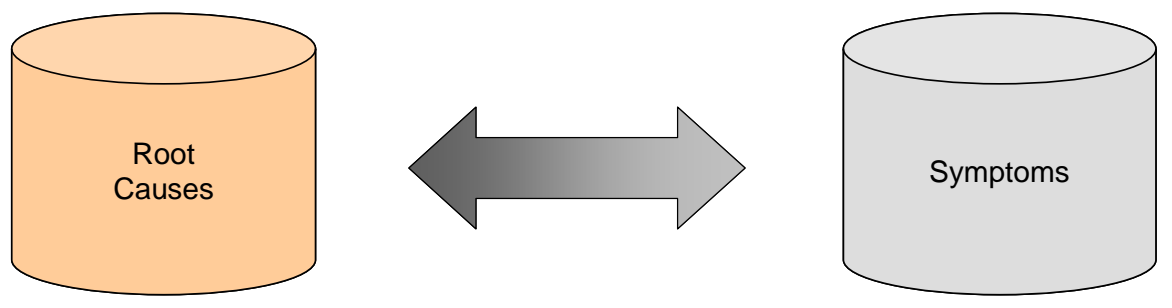

One cause may be related to multiple symptoms.

O One symptom may be related to multiple causes.

The entire list of symptoms, causes and their relationships is usually not known.

If the accuracy of a diagnosis can be improved by collecting more symptoms the system will have to examine the existing data of the network in detail.

Figure 2: Relationship between root causes and symptoms

The overall target of any disruption handling system is the identification and eventually the elimination of the problem's root cause. This is where decision support systems (DSS) come into play. Here, diagnostics and therapeutics have long been a major research topic [Pupp91], but so far most of these systems did not fit satisfactorily into an enterprise or networked environment [WaL+02].

Having alleviated the symptom and conducted the diagnostic analysis, the last missing step is to move to a full-scale therapy. Therefore, the effect of any counteractions on the supply net needs to be simulated. Based on these results the orchestrator might engage in therapeutic measures and conclude the symptom-totherapy cycle. These therapies are usually of a very strategic nature and have a direct impact on the underlying structure of the network. In most cases, interorganizational processes will have to undergo redesign or non-performing partners will have to be replaced.

To guarantee a close integration of manual and computational activities, it must be possible for a human decision-maker to get involved at all times. Contrary to the aim of most classical expert systems, the unstable and often unpredictable environment of networked organizations forces decision support to not solely rely on mathematical algorithms to calculate solutions or alternatives [BeR+02]. We thus do not only rely on expert systems but the interaction of the described core components. 


\subsection{Impact Analysis}

After disruptions have been recognized and reported to the central reaction system, it is important to gauge their impact on the entire chain. Not only should the actual problem be considered in this analysis, but also the question if a series of small exceptions might add up to a major deadlock [Zell02].

Depending on this impact other participants of the supply net will have to be informed. The basic idea at this point is not to disseminate any unnecessary information to stakeholders not readily needing it but instead supply it to them right at the moment they require it [DaGl02]. Thus we need to filter all incoming alerts according to their impact.

In other words, if a truck breaks down and will be one day late, the goods, however, will not be needed for another two days, the system must only inform those parties scheduled to receive them. Otherwise the network would face an information over-flow and thereby reduce the quality of decisions made [WeK+01]. Contrary, should the system detect the ultimate customer is influenced in any kind all upstream stakeholders will require this information.

The graph theory and its implementation in information systems [Sedg01] represent an easy way to bring the impact analysis to live. If the time buffer at a certain node overcompensates any delays at upstream-level echelons, the disruption will not affect finished goods and delivery to the ultimate customer. Of course, other factors like capacity and budget constraints of individual echelons also have to be considered to evaluate the big picture. Another influence of utmost importance is the classification of the affected clients. Applying an ABC evaluation [MeS+03], re-solving problems concerning A-clients must be given the highest priority.

Moving one step further the impact analysis will add the likelihood of certain disruptions to better evaluate what really might happen in the overall chain. Therefore, time series of disruption data are employed to calculate the odds of each exception. The impact analysis now checks the reported problem against these typical disruptions, ranked by their computed probability. Figure 3 demonstrates this principle. 


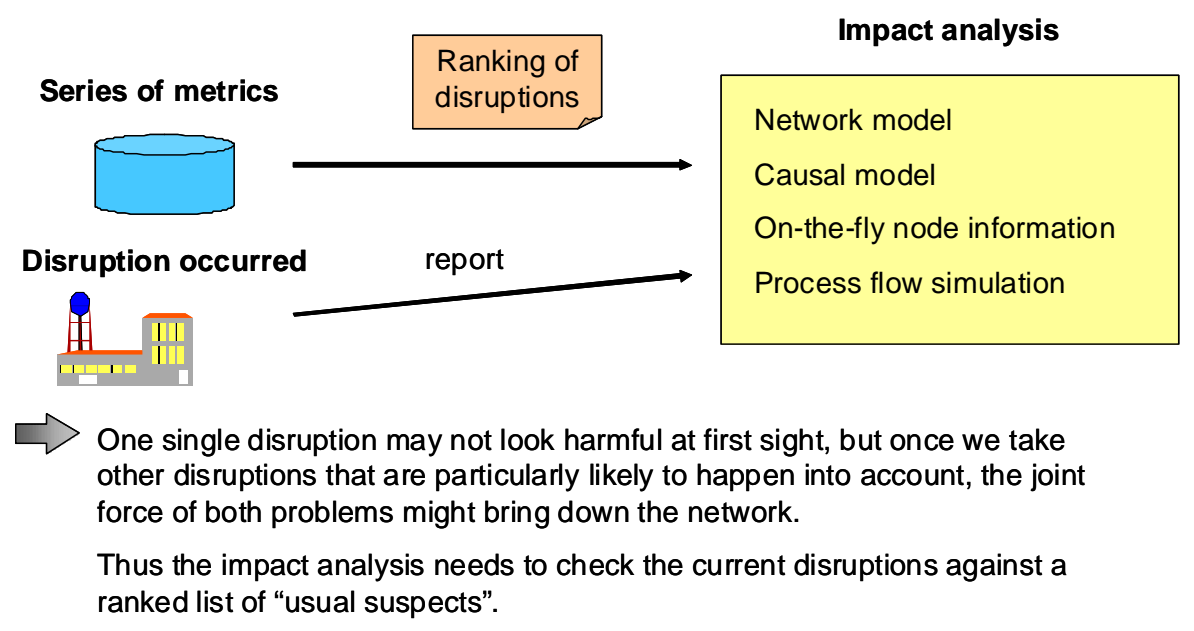

Figure 3: Gauging the impact of multiple disruptions

\subsection{Flexible integration using web services}

The problem with most traditional supply chain management systems is their inherent need for a time consuming and costly integration of the software used by all participants in the supply chain. Unfortunately, this setback can lead to other problems. Once the incorporation of the different systems has been accomplished the nodes are coupled in a very tight way which leads to a rigid formation of enterprises rather than a flexible, agile and loosely coupled network. Especially for SME the decision to step in a supply chain and the costs associated with it are most likely irreversible and the installed system can therefore thwart the ability to form new partnerships with other companies.

For that reason, one goal of the approach of using the web services architecture to share data across the network is to overcome the mentioned problems with monolithic systems. In case a disruption occurs, a possible reaction could be to query Universal Description, Discovery and Integration (UDDI)-registries in order to find potential suppliers for a substitute. With the help of the Web Services Description Language (WSDL), companies can expose their supply chain functionalities, as well as the expected format and semantic aspects. Web services might be seen as an advancement of the componentware approach, where functionality is encapsulated in software modules (information hiding). The possibility to seclude methods can be utilized to continue to use already available legacy systems. Another advantage of web services is that they build upon widespread and wellknown standards and protocols like HTTP or XML. Particularly in the area of transportation web services can be combined with new developments like smart 
phones or Personal Digital Assistants (PDA) to quickly report breakdowns or delays and to receive immediate instructions on how to react to the disruption.

Cap Gemini Ernst \& Young conducted a survey in June 2002, in which 108 companies were asked to give their opinions regarding the potential use and fields of application. Figure 6 shows the goals which decision-makers plan to achieve with the introduction of web services. Of special interest to us are the mentioned improvements in flexibility and the potential ease of integration. In addition, market analyst IDC [IDC03] predicts that by the year 2008 almost $80 \%$ of U. S. enterprises will be employing web services.

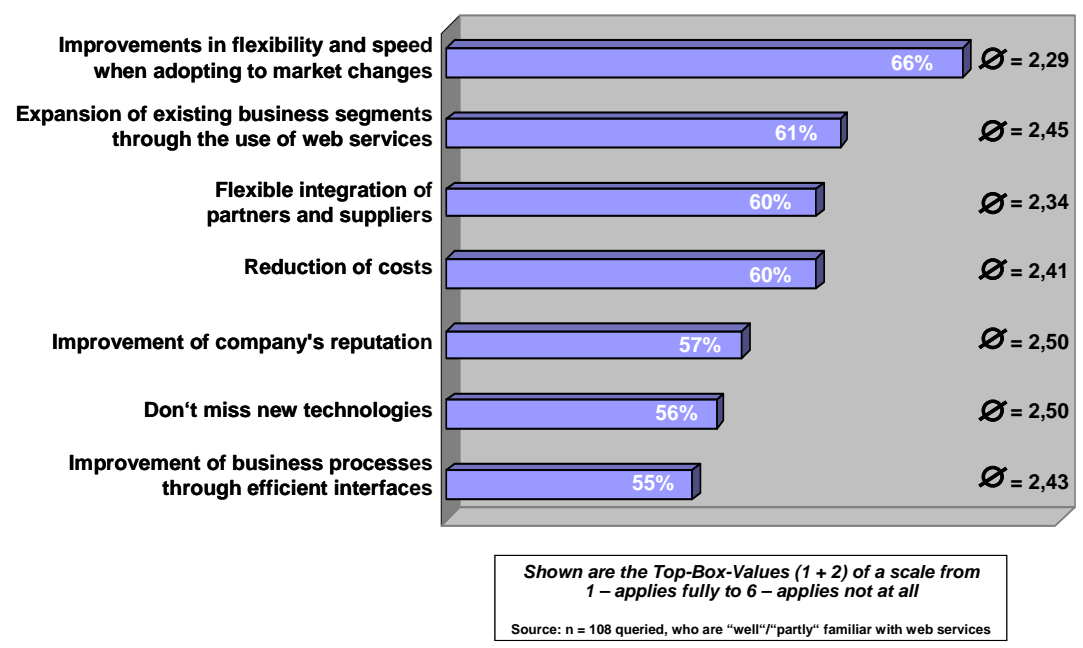

Figure 4: Goals by using web services (based on Cap Gemini Ernst \& Young [CGEY02])

Nevertheless, standards like UDDI or WSDL have to be seen as a work in progress right now, and some aspects need further developments, e. g. security or transaction management. Because we clearly see advantages of web services in the area of flexible integration, we decided to deploy them in our prototypical implementation as the foundation for performance and disruption management.

\section{Prototype - from theory to practice}

FORWIN is currently implementing a prototype to realize the above described functions. Some of the methods, as well as all messaging components will be build using web services technologies. In the first step of the project we concentrated on the design of the data model and the ability to discover and visualize oc- 
curring disruptions. In the future we plan to enhance the system. Our goal is to offer functionality that covers all aspects of the afore mentioned symptom-to-therapy cycle.

\subsection{Architecture}

The dilemma when we began to develop the prototype could be summarized with the saying: "The best thing about standards is that there are so many to choose from.", which is attributed to Andrew Tanenbaum. Both available platforms, Sun's Java ${ }^{\mathrm{TM}} 2$ Enterprise Edition (J2EE ${ }^{\mathrm{TM}}$ ) and the .NET ${ }^{\mathrm{TM}}$ framework from Microsoft ${ }^{\circledR}$ have their advantages and disadvantages. We finally decided to go with the .NET approach, since web services can be implemented and used in a very convenient way. Furthermore, there is no need to agree upon a certain solution like Apache SOAP or the Web Services Toolkit offered by IBM.

Figure 9 shows the basic architecture concept of the .NET platform for the implementation and deployment of web services. The Common Language Runtime (CLR) is the foundation of the framework. It offers services such as garbage collection, type checking, Just-in-Time (JIT) compilation and takes care of the exception handling. The ActiveX Data Objects.NET (ADO.NET) layer is objectoriented and based on the open XML standard. It offers functions for manipulating data in databases using either the structured query language (SQL) or preferably the ADO programming model and has built-in methods to operate with different XML data structures. The topmost block represents the Active Server Pages.NET (ASP.NET), which include components for server-side web forms and web services or methods to realize a session and state management. The source and page layout can be stored in separate files and the code is compiled instead of being interpreted. 


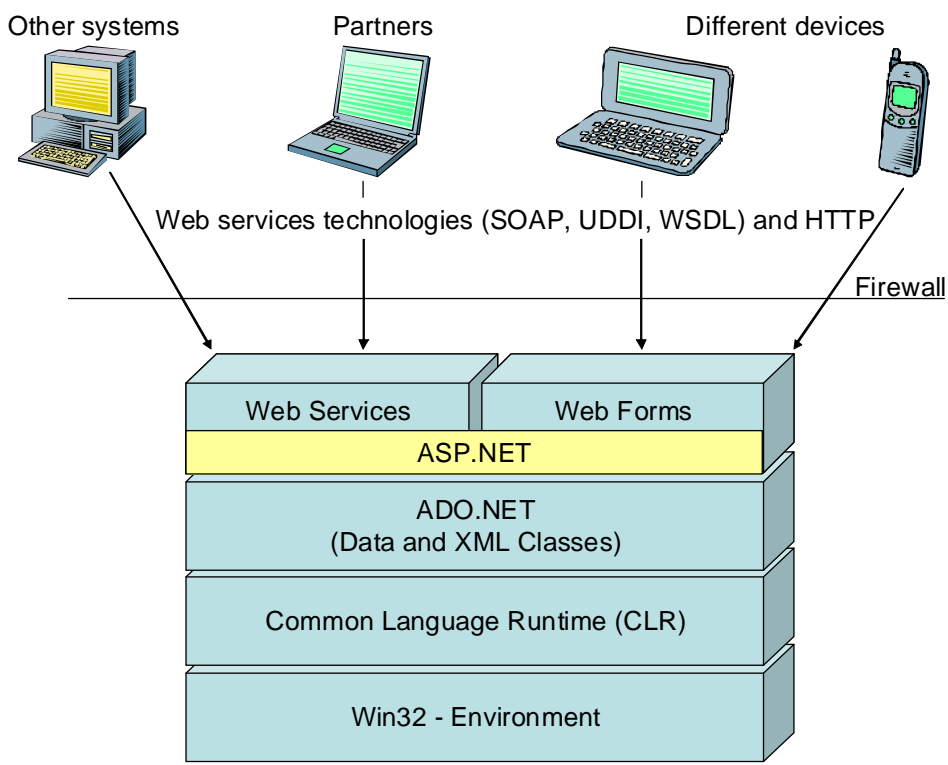

Figure 5: Basic architecture of the .NET-based prototype

\subsection{Data model}

Our first approach to design the underlying data model of the prototype was to simply map the structure of networked organizations into a relational schema. Unfortunately, this procedure did not satisfy the requirements of a system that should be capable of handling disruptions. Besides the data of all involved companies, the system needs to have the ability of tracking the flow of goods and information among them over long periods. Therefore the database must provide relations for storing process flows and the actual position within them. One could think about this part of the model as a workflow engine. The difference to traditional workflow management systems is that they usually focus on inner-organizational process improvements, while the application presented in this paper tries to ease problems in a supply chain. Figure 6 shows the important parts of the model. Some tables of the schema have been omitted for the sake of clarity (tables concerned with the storage of different metrics, user master data and risk management).

The model can be virtually divided into two parts. The tables in the upper and middle parts reflect project and business objects in general, while the lower relations are used to store conditions of the supply network during execution of a specific task. With the object-oriented programming paradigm in mind, one could think about this as the distinction between classes and instances. The following sections describe the use of the different tables in more detail. 
The sco_registry keeps every entity of the supply chain which could be of interest during runtime of the system. This not only includes the objects that the application is monitoring, but also alternatives which should be considered in the case a disruption occurs, e. g. data of car rental agencies or equivalent products.

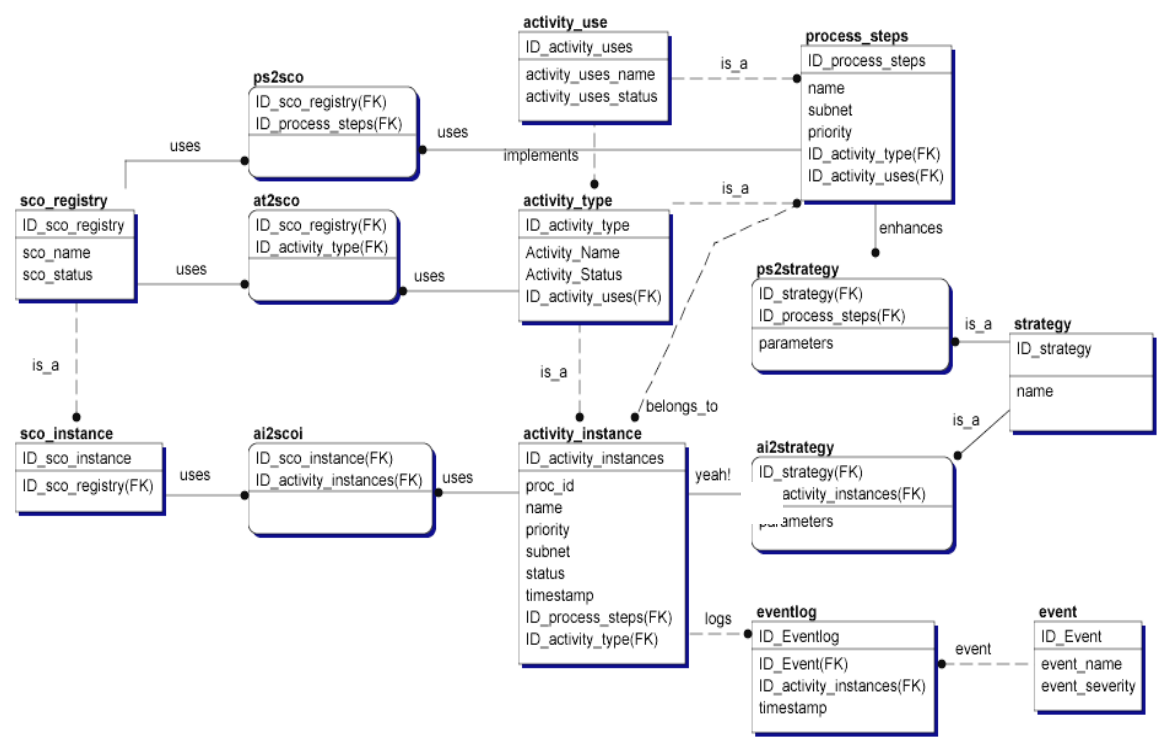

Figure 6: Excerpt of the data model used in the prototype

Activities are stored in the activity_use relation. The granularity of functions is arbitrary and depends on the respective situation, but normally the tuples represent an action which consists of several single steps instead of an atomic task. Data entered in here does not yet determine a detailed execution plan or the allocation of certain resources. The information just generally describes an operation, but does not say anything about how it is accomplished, for example procurement of screws.

As already mentioned above, the activity_use relation holds general descriptions of tasks. To precisely specify these granular operations the activity_type table is used. Among other attributes which are employed to check the status or reference further characteristics of an activity_type, each row has an unique, human understandable name. For example, think of a tuple "sending order data" in the activity_use table. Entries in the type schema could include "transmission of order data via phone" or "transmission of order data by mail". In fact, this behavior can be seen as the implementation of generalization and specialization used in object-oriented approaches.

For each entry in activity_use or activity_type respectively a sequence of single operations can be defined in the process_steps table. As already mentioned in the 
first paragraph of this section, the different tasks are modeled as a workflow. Predecessor nodes and successor elements may be linked directly, but it is also possible to represent split and join conditions. To avoid redundancy to the extend to which it seems applicable, workflows can be combined out of smaller ones. The subnet field shown in figure 6 therefore keeps references to the primary key of the process_steps relation itself, thereby allowing the application to recursively traverse the table. A detailed explanation on how the workflows are mapped into the database schema is given in [SpSt99].

As soon as a process is executed the involved supply chain objects and the associated activity_types are instantiated. It is right in this stage where the transition from the conceptional phase to runtime happens. The sco_instance and activity_instance are used to track the progress of each step. Several attributes like status, duration or estimated finishing time are stored. Not shown in figure 6 are the metrics relations which hold measurements for example the estimated duration of shipments or the expected time it takes for goods to be discharged. It depends on the type of activity what performance indicators are relevant or needed in order to monitor the advancement of the process.

Should a divergence between real values and the predetermined metrics be discovered, the incident will be logged in the event_log table. Depending upon the amount of exceedence compared to a parameterizable threshold for each metric, the severity is determined.

\section{Areas for future study}

This paper discussed several aspects of disruptions in supply chains from a theoretical point of view. Based on these findings we started to implement functions to visualize problems occurring in networks. While the methods needed to check whether disruptions happening in one entity may cause trouble in other nodes of the supply net are already in place, there is still a lot of work to do in the field of diagnostics and therapy.

Another interesting facet is the potential incorporation of externally available data into the disruption management system. By establishing a continuous information screening of additional sources it seems possible to automatically prevent disruptions before they occur. Closed mountain roads due to heavy snowfall can be seen as an example for such external facts. Giving the system access to these types of information it can reschedule deliveries or reroute transports while parts of the whole business process may already be in execution.

A lingering question is in how far the human decision-maker should be involved with the system. Following Mertens' paradigm of the reasonable full automation 
(original: sinnhafte Vollautomation) [Mert95] the responsible manager must be given the freedom to choose from a variety of options.

We are keeping an eye on current and future developments around different web services technologies. Interesting areas that are important to productive systems include transaction management and security issues like message signing, secure data transmission or authentication.

Already planned is a research on evolving techniques to support the flow of shipping operations and other logistics processes. Quite a few companies were working on this subject during the past years. Among others, Microsoft suggested the XLANG specification [That01] while IBM promoted its Web Service Flow Language (WSFL) [Leym01]. Unfortunately these protocols were not designed to work together. But it seems that the former competitors are now joining forces to work on a common specification called Business Process Execution Language for Web Services [BPEL4WS]. It is a XML-based standard that allows the description of business tasks and the modulation of sequences in order to enable crossenterprise business process automation.

\section{References}

[BeMe96] Belz, R., Mertens, P.: Combining knowledge-based systems and simulation to solve rescheduling problems. Decision Support Systems, 17 (2), 1996, pp. 141-157.

[BeR+02] Beynon, M., Rasmequan, S., Russ, S.: A new paradigm for computer-based decision support. Decision Support Systems 33, 2002, pp. 127-142.

[Bret02] Bretzke, W.-R.: Supply Chain Event Management. Mehr als nur ein Schlagwort in der Logistik. Mylogistics News 2002-02-20. http://www.mylogistics.net/de/news/ print_themen1.jsp?key=news25886, 2002., Download 2003-02-03.

[BuKo00] Buxmann, P., Koenig, W.: Inter-organizational Cooperation with SAP Systems Perspectives on Logistics and Service Management. Springer: Berlin et. al., 2000, p. 52.

[CGEY02] Cap Gemini Ernst \& Young: Der Markt für Web-Services - Erwartungen, Treiber, Investitionsabsichten. Cap Gemini Ernst \& Young. http://www.de.cgey.com/ servlet/PB/show/1004620/Web-Services.pdf, 2002, Download 2002-12-13.

[DaGl02] Davenport, T., Glaser, J.: Just-in-Time Delivery Comes to Knowledge Management. Harvard Business Review, 81 (7), 2002, pp. 107-111.

[DoK+02] Dorer, K., Kammerer, K., Fritschi, C.: Agentenorientiertes Design für vernetzte Maerkte. In Weinhardt, C., Holtmann C. (Eds.), E-Commerce: Netze, Maerkte, Technologien. Heidelberg: Physica, 2002, pp. 55-66.

[Frie02] Friedrich, J-M.: Supply-Chain-Management-Software für kleine und mittlere Unternehmen - Lösungsmöglichkeiten mit Componentware. Shaker-Verlag. Aachen 2002 . 
[FrSp03] Friedrich, J.-M.; Speyerer, J.: Flexible Integration in Supply Chains auf Basis von Web Services. Accepted paper for 5. Paderborner Frühjahrstagung - Innovationen im E-Business. Fraunhofer Anwendungszentrum für Logistikorientierte Betriebswirtschaft.

[GaWa02] Garcia-Flores, R., Wang, X. Z.: A multi-agent system for chemical supply chain simulation and management support. OR Spectrum 24 (3), 2002, pp. 343-370.

[Hebe02] Hebert, Lisa: The Logistics Footprint - Creating a Road Map to Excellence. In: Ascet Volume 4. 2002-05-15. http://www.ascet.com/documents.asp?d_ID=972. Download 2003-02-03.

[IBM02] International Business Machines Corporation (Ed.): Business Process Execution Language for Web Services, Version 1.0 - 31.July.2002.

ftp://www6.software.ibm.com/software/developer/library/ws-bpel.pdf, 2002-07-31, Download 2002-11-20.

[IDC03] IDC: Web Services Are Becoming Reality: IT Opportunity Around Web Services Will Reach $\$ 21$ Billion by 2007. 2003-02-04. http://www.idc.com/ getdoc.jhtml?containerId=pr2003_02_03_130651, Download 2003-02-05.

[Knic01] Knickle, K.: Supply Chain Event Management - The Next Best Thing to Supply Chain Perfection. AMR Research. AMR Research Outlook. 2001-10-29. http://www.amrresearch.com/content/printversion.asp?i=652, 2001, Download: 200206-12.

[Kreb02] Krebs, W.: Optimierung einer Wertschöpfungskette am Beispiel des Projektes CoagenS. In: Dangelmaier, W., Emmerich, A., Kaschula, D. (Eds.): Modelle im EBusiness. ALB-HNI-Verlagsschriftenreihe: Paderborn, 2002, pp. 123-139.

[LaPo01] Lambert, D. M., Pohlen, T. L.: Supply Chain Metrics. The International Journal of Logistics Management 12 (1), 2001, pp. 1-19.

[LeAm02] Lee, H. L., Amaral, J.: Continuous and Sustainable Improvement Through Supply Chain Performance Measurement. Stanford Global Supply Chain Forum. White Paper. http://www.stanford.edu/group/scforum/Welcome/SCPM.pdf, 2002, Download 2003-02-03.

[Leym01] Leymann, F.: Web Services Flow Language (WSFL 1.0). http://www3.ibm.com/software/solutions/webservices/pdf/WSFL.pdf, 2001-05-01, Download 2002-10-08.

[MaSu02] Martha, J.; Subbakrishna, S.: Targeting a Just-in-Case Supply Chain for the Inevitable Next Disaster. Supply Chain Management Review Online. http://www.manufacturing.net/scm/index.asp?layout=articleWebzine $\&$ articleid=CA243 747. 2002-10-01. Download 2003-02-03.

[MeS+03] Meier, M., Sinzig, W.; Mertens, P.: Strategic and Operational Management with SAP SEM/BA. Springer: Berlin, 2003.

[Mert95] Mertens, P.: Wirtschaftsinformatik - Von den Moden zum Trend. In: König, W. (Ed.): Wirtschaftsinformatik '95. Heidelberg 1995, pp. 25-64.

[Mert02] Mertens, P.: Business Intelligence - ein Überblick. Information Management und Consulting. Special Edition, 2002, pp. 65-73. 
[MuLe02] Mulani, Narendra; Lee, Hau L.: New Business Models for Supply Chain Exellence. In: Ascet Volume 4. http://www.ascet.com/documents.asp?d_ID=1084, 2002-0515, Download 2003-02-03.

[Niss02] Nissen, V.: Supply Chain Event Management als Beispiel fuer Electronic Business in der Logistik. In: Gabriel, R., Hoppe, U. (Eds.): Electronic Business - theoretische Aspekte und Anwendungen in der betrieblichen Praxis. Physica: Heidelberg, 2002, pp. 429-445.

[Pati02] Patig, S.: Flexible Produktionsfeinplanung mit Hilfe von Planungsschritten - Ein Planungsansatz zum Umgang mit Störungen bei der Produktion.Europäischer Verlag der Wissenschaften: Frankfurt am Main, 2001.

[Pupp91] Puppe, F.: Einführung in Expertensysteme (2nd ed.). Springer: Berlin et al., 1991.

[Sedg01] Sedgewick, R.: Algorithms in C++, Part 5: Graph Algorithms (3rd Edition). Addison Wesley Professional: Boston, 2001.

[Spey00] Speyerer, J.: Conception and Implementation of a Simplified Available-toPromise Logic for Small and Medium Sized Enterprises with Componentware. Unpublished master's thesis, Friedrich-Alexander University of Erlangen Nuremberg, 2002.

[SpSt99] Speyerer, J., Strohmaier, M.: Dokumenten- und Workflow-Management-Systeme zur Gewinnung von controllingrelevanten Informationen bei einen Maschinenbauunternehmen. Unveröffentlichte Projektarbeit, Friedrich-Alexander-Universität ErlangenNürnberg, 1999.

[That01] Thatte, S.: XLANG - Web Services for Business Process Design. http://www.gotdotnet.com/team/xml_wsspecs/xlang-c/default.htm, 2001, Download 2002-12-10.

[WaL+02] Wang, H., Liao, S., Liao, L.: Modeling constraint-based negotiation agents. Decision Support Systems 33, 2002, pp. 201-217.

[WeK+01] Wettstein, T., Küng, P., Meier, A.: Performance Measurement als Ausweg aus dem Information Overload. In HMD 222, 2001, pp. 49-59.

[WiLa01] Wieser, O., Lauterbach, B.: Supply Chain Event Management mit mySAP SCM (Supply Chain Management). HMD - Praxis der Wirtschaftsinformatik 219, 2001, pp. 65-71.

[Wild95] Wildemann, H.: Entstörmanagement - Realisierung störungsrobuster Wertschöpfungsprozesse. $2^{\text {nd }} \mathrm{Ed}$. Transfer-Centrum: Munich, 1995.

[WoCi99] Wooldridge, M., Ciancarini, P.: Agent-oriented Software Engineering. Handbook of Software Engineering and Knowledge Engineering, 1999, pp.1-13.

[Zell02] Zeller, A. J.: Process and performance decisions in the networked organization: Handling disruptions in supply networks. Presentation 33rd Annual Conference of the Italian Operational Research Society. L'Aquila 2002-09-10. 